\title{
Quantitative transportation assessment in curved canals prepared with an off-centered rectangular design system
}

\section{Emmanuel João Nogueira Leal SILVA ${ }^{(a)}$ \\ Vania Cristina Gomes VIEIRA ${ }^{(a)}$ \\ Michele Dias Nunes TAMEIRÃO(a) \\ Felipe Gonçalves BELLADONNA ${ }^{(b)}$ \\ Aline de Almeida NEVES(c) \\ Erick Miranda SOUZA ${ }^{(d)}$ \\ Gustavo DE-DEUS(a)}

(a) Universidade do Grande Rio - Unigranrio, School of Dentistry, Department of Endodontics, Rio de Janeiro, RJ, Brazil.

(b) Universidade Federal Fluminense - UFF,

Department of Endodontics, Niterói, RJ, Brazil.

(c) Universidade Federal do Rio de Janeiro - UFRJ, School of Dentistry, Department of Pediatric Dentistry and Orthodontics, Rio de Janeiro, RJ, Brazil.

(d) Universidade Federal do Maranhão - UFMA, School of Dentistry, Department of Dentistry II, São Luis, MA, Brazil.

Declaration of Interests: The authors certify that they have no commercial or associative interest that represents a conflict of interest in connection with the manuscript.

Corresponding Author:

Emmanuel João Nogueira Leal Silva

E-mail: nogueiraemmanuel@hotmail.com

DOI: 10.1590/1807-3107BOR-2016.vol30.0043

Submitted: July 20, 2015

Accepted for publication: November 13, 2015

Last revision: January 28, 2016
Abstract: The purpose of this study was to assess the ability of an off-centered rectangular design system [ProTaper Next (PTN)] to maintain the original profile of the root canal anatomy. To this end, ProTaper Universal (PTU), Reciproc (R) and WaveOne (WO) systems were used as reference techniques for comparison. Forty clear resin blocks with simulated curved root canals were randomly assigned to 4 groups ( $n=10$ ) according to the instrumentation system used: PTN, PTU, R and WO. Color stereomicroscopic images of each block were taken before and after instrumentation. All image processing and data analysis were performed with an open source program (Fiji v.1.47n). Evaluation of canal transportation was obtained for two independent regions: straight and curved portions. Univariate analysis of variance and Tukey's Honestly Significant Difference test were performed, and a cut-off for significance was set at $\alpha=5 \%$. Instrumentation systems significantly influenced canal transportation $(p=0.000)$. Overall, $R$ induced significantly lower canal transportation compared with WO, PTN and PTU $(p=0.000)$. The curved portion displayed superior canal transportation compared to the straight one $(p=0.000)$. The significance of the difference among instrumentation systems varied according to the canal level evaluated $(p=0.000)$. In its straight portion, R and WO exhibited significantly lower transportation than PTN; whereas in the curved portion, $\mathrm{R}$ produced the lowest deviation. PTU exhibited the highest canal transportation at both levels. It can be concluded that PTN produced less canal transportation than PTU and WO; however, R exhibited better centering ability than PTN.

Keywords: Endodontics; Root Canal Preparation; Dental Instruments.

\section{Introduction}

The development of novel nickel-titanium (NiTi) based rootcanal preparation systems, such as Reciproc (R) (VDW, Munich, Germany), WaveOne (WO; Dentsply Maillefer, Baillagues, Switzerland) and the recently launched ProTaper Next (PTN; Dentsply Maillefer), have focused primarily on modifications in instrument design, alloy composition and shaping movements.

The most relevant reciprocation systems available on the market $\mathrm{R}$ and $\mathrm{WO}$ - propose using a single file to prepare the root canal, so that it ultimately has a minimum taper-size shape. ${ }^{1,2,3}$ To achieve this, reciprocating techniques normally use large, rigid single files of increased taper, which can result in a higher incidence of canal transportation, 
compared to the progressive filing increase in size and taper, as proposed in multifile rotary systems. ${ }^{3,4,5}$ Furthermore, the lack of a preliminary coronal enlargement, the greater engagement of the flutes, and the higher torque and/or increased applied pressure in reciprocating techniques could contribute to greater canal transportation. ${ }^{1,2,3,4,5}$

In contrast, the multifile PTN system seeks to improve the strength and flexibility along the active part of the file, by incorporating a progressive and regressive taper design, and using an innovative off-centered rectangular design. ${ }^{6}$ This specific design enables an asymmetric rotary motion intended to decrease the screw-in effect, minimizing the contact area between the file and the dentinal walls. ${ }^{7}$ This could be especially important when navigating challenging curves in the apical region, thus minimizing canal transportation.

Investigations of the shaping effect promoted by these new NiTi systems are becoming more important, because they help understand how the file design and different kinematics affect NiTi system performance. ${ }^{8}$ Simulated curved canals in resin blocks have been traditionally used to evaluate some aspects of the shaping ability, including canal transportation and centering ability of different NiTi systems. ${ }^{9,10}$ However, a major limitation of most proposed evaluation methods is the need of operator intervention to preselect the evaluation points required to ultimately obtain the transportation measurements. An interesting root transportation analysis in simulated canals has been recently proposed. It uses an automatic approach that measures the entire simulated canal without operator intervention. ${ }^{11}$ This innovative method offers some improvements, including much less operator input and reduced bias, thus providing results for the evaluation of the whole canal length instead of just preselected slices.

The present study was designed to assess the ability of PTN system to maintain the original profile of root canal anatomy using simulated curved canals in resin blocks. ProTaper Universal (PTU; Dentsply Maillefer), R and WO systems were used as the reference techniques for comparison. A recently published methodological approach was used to automatically register the images before and after instrumentation and to use a skeletonization algorithm to calculate the canal centering ability. The null hypothesis tested was that there are no significant differences in canal transportation between the PTN and the other tested NiTi systems.

\section{Methodology}

\section{Digital image acquisition}

Forty simulated curved root canals in clear resin blocks (Endo Training Blocks ISO 15; Dentsply Maillefer), with $2 \%$ taper, $10 \mathrm{~mm}$ radius of curvature, $70^{\circ}$ angle of curvature and $17 \mathrm{~mm}$ in length, were randomly assigned to 4 groups $(n=10)$ according to the instrumentation system used: PTN, PTU, R and WO. Before performing any instrumentation procedures, a round silicon base with a rectangular slot was fit onto the microscope base of a color stereomicroscope (1005t Opticam stereomicroscope; Opticam, São Paulo, Brazil) coupled to a digital camera (CMOS 10 megapixels; Opticam, São Paulo, Brazil). The rectangular slot matched the exact dimensions of the simulated canal blocks. Each specimen was then inserted into the slot, and color images were taken and stored in TIFF format. Following the instrumentation procedures, all blocks were imaged again, using the same protocol.

Ten resin blocks were used as a control group in which no instrumentation was performed, in order to check the reliability and consistency of the repositioning method. In this group, one color stereoscopic image of each block was taken. Afterwards, the block was removed, and replaced after another image taken.

\section{Instrumentation}

In all groups, a stainless steel 10- and 15 K-files (Dentsply Maillefer) scouted the canal up to the working length (WL), creating an initial and standardized glide path.

PTN. The canals were prepared with PTN instruments used at $300 \mathrm{rpm}$ with $2 \mathrm{Ncm}$ torque (VDW Silver). The X1 (17/0.04) and X2 (25/0.06) files were used sequentially at the full WL.

PTU. The canals were prepared with PTU instruments used at $300 \mathrm{rpm}$ with $2 \mathrm{Ncm}$ torque (VDW Silver). The following sequence was used: SX file (19/0.04) $(1 / 2$ of the WL); S1 file (18/0.02) (2/3 of the WL); S2 file (20/0.04) (2/3 of the WL); F1 (20/0.07) and F2 (25/0.08) files (full WL). 
R. The canals were prepared with R25 (25/0.08) instruments used according to the pre-setting program (RECIPROC ALL), powered by a torque-controlled motor (VDW Silver). The instrument was gradually advanced in the root canal until it reached $2 / 3$ of the $\mathrm{WL}$, and then moved in a slow and gentle in-and-out pecking motion with $3 \mathrm{~mm}$ amplitude limit. After each three complete pecking movements, the instrument was removed from the canal and its flutes were cleaned by insertion into a clean stand with a sponge.

WO. WO Primary (25/0.08) files were used similarly to the R group, according to the WAVEONE ALL presetting program.

All instrumentation procedures were performed by a single operator with experience in rotary and reciprocating motions, and only new instruments were used. Apical patency was confirmed between each preparation step, using a size $10 \mathrm{~K}$-file just beyond the $\mathrm{WL}$, and the canals were irrigated with $1.0 \mathrm{~mL}$ sterile water using a 30-G side-vented needle (Max-i-Probe; Dentsply Rinn, Elgin, USA) placed to a depth just short of binding. After final irrigation with $1.0 \mathrm{~mL}$ sterile water, post instrumentation images were performed as described earlier.

\section{Image processing and analysis}

All image processing, registration, segmentation and extraction of attributes were performed with the FIJI open source software interface (Fiji v.1.47n; Madison, USA) or one of its associated plugins. ${ }^{12}$ Image processing and analysis were based on previously described methodology. ${ }^{11}$ Briefly, the images were first converted to an 8-bit grayscale, after which each pair of images (baseline and after instrumentation) was registered using the "Rigid Registration" plugin. The baseline image was used as the template for the rigid transformation. A composite image of the baseline and the instrumented canal after registration can be seen in Figure 1A.

Each canal (baseline and instrumented) was then segmented from the background using an iterative polygon tracing tool. Each line segment was defined by the user, following the geometry of the canal, and aided by an automatic segmentation algorithm to appropriately define the edges. After defining the polygon, a simple binarization scheme $(0$ for background, 255 for the defined polygon) was applied (Figure 1B). A skeletonization algorithm, ${ }_{1}^{11}$ which uses a symmetrical erosion procedure to find the centerline of the segmented images, was applied. An example of the final centerline of each baseline and instrumented canals is depicted in Figure 1C. The XY coordinates of each skeleton were exported to a spreadsheet, and the difference between each $X Y$ coordinate for the baseline and the instrumented skeleton images was calculated using the following formula:

$$
\sqrt[2]{\left(x_{b}-x_{i}\right)^{2}+\left(y_{b}-y_{i}\right)^{2}}
$$

where: $x_{b}$ and $y_{b}$ are the coordinates for the baseline canal, and $x_{i}$ and $y_{i}$ are the coordinates for the instrumented canal.

Transportation measurements were obtained by converting the values obtained to millimeters (mm) with the aid of the microscope magnification scale. Transportation values were then averaged for the whole canal or for two independent regions (straight and curved portions), as seen in Figure 2A, which shows the artificial canal image and the regions analyzed.

\section{Statistical analysis}

Both canal portions generated several deviation values (straight $=26,360$ and curved $=33,600$ ), corresponding to each pixel evaluated. Each pixel was considered as a unit for statistical analysis purposes. Considering the data size, a bell-shaped distribution was assumed, and a univariate analysis of variance (two-way) procedure, with a cut-off significance level of $a=5 \%$, was selected, considering the instrumentation

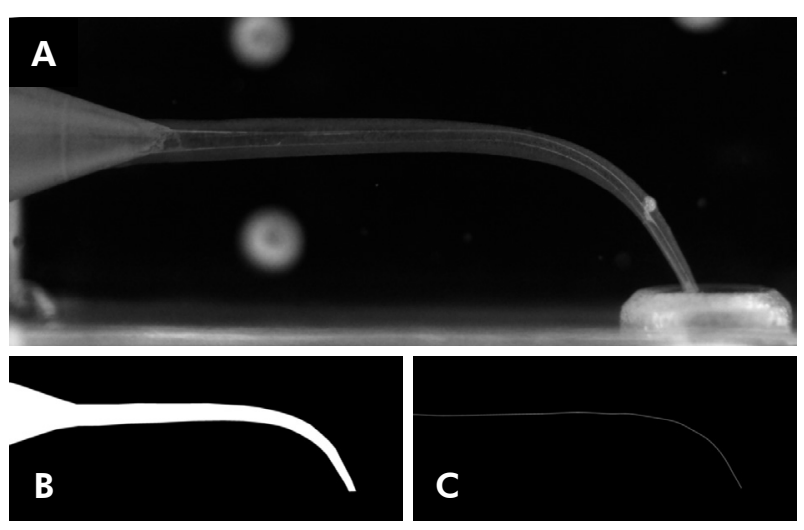

Figure 1. (A) Composite image of superposition of sound and instrumented canals after image registration; (B) Segmented instrumented canal; (C) Skeleton of instrumented canal. 
systems and the root canal portion as independent variables, and canal transportation (in $\mathrm{mm}$ ) as the dependent. Tukey's Honestly Significant Difference test was used for pair-wise comparisons.

\section{Results}

No canal transportation was observed in the control group, confirming the reliability and consistency of the method. Instrumentation systems significantly influenced canal transportation $(p=0.000)$. Considering the overall canal length, $R(0.061 \pm 0.049)$ induced significantly lower canal transportation compared with WO $(0.063 \pm 0.060)$, PTN $(0.072 \pm 0.062)$ and PTU $(0.082 \pm 0.066)(p=0.000)$. Canal transportation was more severe in curved canal portions (0.091 0.066) when compared to straight portions $(0.042 \pm 0.037)$ $(p=0.00)$, as seen in Figure 2B. A significant interaction between the instrumentation systems and the root canal portion $(\mathrm{p}=0.000)$ indicated patterns of different effect for the instruments, according to the canal level, as follows: in the straight portion, similar
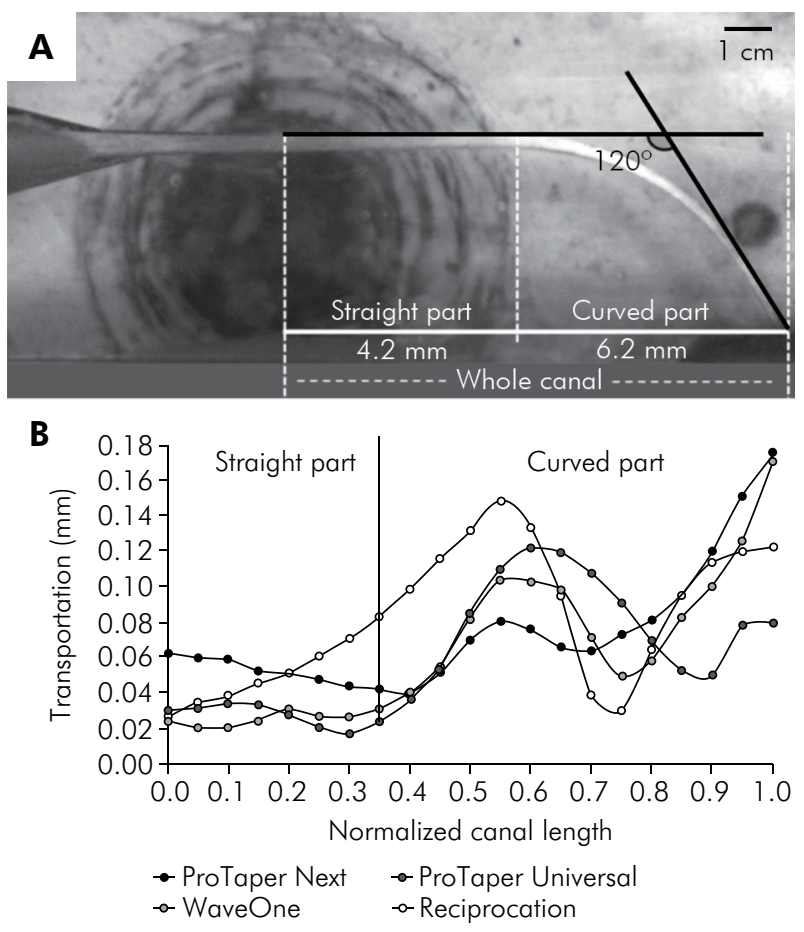

Figure 2. (A) Schematic representation of the straight and curved canal regions evaluated in the present study. (B) Mean transportation values in simulated canals for each instrumentation group and canal portion. canal transportation was observed for WO and R; this result was found to be significantly lower for PTN; in the curved portion, $\mathrm{R}$ produced the lowest canal transportation. WO and PTN produced similar results. PTU exhibited the greatest transportation values in both canal portions (Table).

\section{Discussion}

The present study used a recently described methodology to study transportation in simulated root canals, by comparing images registered before and after instrumentation with different systems. ${ }^{11}$ This method considerably reduces the bias related to a subjective, visually driven or operator-based image superimposition scheme and canal transportation evaluation, ${ }^{2,3,9,10}$ since it is virtually not dependent on user input, and also gives information on the whole canal length, instead of only preselected slices. Although the two-dimensional approach represents a clear limitation of the method, it is important to point out that current three-dimensional-based techniques used to evaluate root canal transportation have not yet provided fully quantitative volumetric data, $, 5,13,14,15,16,17$ resulting in the evaluation of limited selected slices and manual selection of gravity center points.

Simulated artificial canals have already been validated as satisfactory models to study the shaping ability of endodontic instruments. ${ }^{2,3,4,9,10}$ These models are especially attractive, because they fully standardize the canal anatomy. However, there are some limitations. These include the difference in microhardness between manufactured resin and root dentin, ${ }^{9}$ and the potential side effects created by heat generation during instrumentation, which may soften the resin material and bind the cutting blades of the instruments. ${ }^{2,3,4,9,10,11}$ For this reason, care should be taken before extrapolating these results directly to a clinical situation.

During the investigation of the shaping ability of NiTi systems, it is important to standardize not only the tip size but also the taper of the last file used during root canal preparation. For this reason, this study used R R25 and WO Primary files for the reciprocation systems; while PTN X2 and PTU F2 instruments were used in the multifile systems. Therefore canal preparation was standardized to 
Table. Mean, standard deviation (SD) and 95\% Confidence Interval (CI) for the interaction between instrumentation systems and canal portion.

\begin{tabular}{lccc}
\hline Canal Portion & Instrumentation System & Mean (SD) & $95 \% \mathrm{Cl}$ \\
\hline \multirow{4}{*}{ Straight } & WaveOne (WO) & $0.028(0.030)$ & $0.027-0.030^{\circ}$ \\
& Reciproc (R) & $0.029(0.023)$ & $0.028-0.030^{\circ}$ \\
& ProTaper Next (PTN) & $0.050(0.037)$ & $0.049-0.052^{\mathrm{b}}$ \\
& ProTaper Universal (PTU) & $0.060(0.043)$ & $0.058-0.061^{\mathrm{c}}$ \\
Curved & WaveOne (WO) & $0.090(0.065)$ & $0.088-0.091^{\mathrm{B}}$ \\
& Reciproc (R) & $0.086(0.050)$ & $0.085-0.087^{\mathrm{A}}$ \\
& ProTaper Next (PTN) & $0.090(0.072)$ & $0.088-0.090^{\mathrm{B}}$ \\
\hline
\end{tabular}

Different low or capital letters indicate significant differences as depicted from the $95 \% \mathrm{Cl}$, respectively at straight and curved canal portions.

a final shape of ISO 25 tip size with a taper of 0.08 over the first $3 \mathrm{~mm}$ for all tested systems, except for PTN, which has a taper of 0.06 over the first $3 \mathrm{~mm}$. Taper and cross-sectional design could explain the better results observed herein in the PTN group, as compared with the PTU and WO systems.

The clinical applicability of the current canal preparation results using only one instrument is indeed very attractive. Reciprocating motion is known to improve the canal centering ability and to reduce the risk of root canal aberrations. ${ }^{18,19} \mathrm{In}$ this study, R system showed significantly less canal transportation in relation to the overall canal length. Therefore, the null hypothesis tested was rejected. It is important to point out that the difference between the reciprocating systems ( $\mathrm{R}$ and WO) was numerically very low $(0.002 \mathrm{~mm})$, as compared with the numerical difference between the mean transportation values in reciprocating and multifile rotary systems $(0.01-0.02 \mathrm{~mm})$, in relation to the entire canal length. Despite the fact that $\mathrm{R}$ and WO instruments have some similarities, such as the reciprocating motion per se and the same special heat-treated M-wire alloy and tip size, ${ }^{20,21,22}$ the former showed significantly less transportation in the curved portion of the canal. These results may be explained by their different cross-sectional designs; whereas $\mathrm{R}$ has a double-cutting edge S-shaped geometry, WO has a modified, convex, triangular cross-section with radial lands at the tip, and a convex triangular cross-section in the middle and coronal portion of the file, with a larger cross-sectional area when compared to R. ${ }^{20}$
This larger cross-sectional area influences the bending resistance of the instrument, ${ }^{23}$ making it less flexible and thus increasing the straightening trend in curved canals. The larger cross-sectional area of PTN and PTU may also substantiate the differences between these and R. In addition, other variables such as the screw-in effect, which usually occurs with active instruments that rotate under continuous rotation motion, ${ }^{24,25}$ and the total number of used instruments, may explain the results obtained by PTN and PTU herein. Overall, PTU system showed the highest canal transportation mean $(0.082 \mathrm{~mm})$, which may be explained by its traditional NiTi alloy, which noticeably affects stress-strain distribution patterns and bending ability, making PTU much less flexible.

The outperformance showed by the $R$ system contrasts with some recent studies, which have shown no differences regarding shaping outcomes, compared to other NiTi systems. ${ }^{20,21,22}$ Çapar et al. ${ }^{20}$ showed similar canal curvature modifications among OneShape (Micro-Mega, Besançon, France), PTU, PTN, R, WO and Twisted File Adaptive (SybronEndo, Orange, CA) systems in the mesial root canals of mandibular molars, and Saber et al. ${ }^{21}$ showed no differences in the overall shaping ability of R and WO in curved root canals using digital radiographs. Bürklein et al. ${ }^{22}$ have also shown no differences among R, WO, PTU and Mtwo (VDW) systems in extracted teeth using digital radiography to evaluate their shaping ability. These contradictory results could be attributed mainly to the differences in the magnitude of the resolution employed by these studies, which are about $10^{-1} \mathrm{~mm}$, 
compared to the present study, where resolution was increased to about $10^{-3} \mathrm{~mm}$, which can considerably increase the effect of small differences among the instrumentation systems. Whether the difference achieved herein is of clinical significance is a matter of further debate. Other factors, including instrument design, alloy composition, instrumentation technique and root canal anatomy, are also known to cause an impact on canal transportation ${ }^{26}$ and may account for the present results.

\section{References}

1. De-Deus G, Arruda TE, Souza EM, Neves A, Magalhães K, Thuanne E, et al. The ability of the Reciproc R25 instrument to reach the full root canal working length without a glide path. Int Endod J. 2013;46(10):993-8. doi:10.1111/iej.12091

2. Berutti E, Paolino DS, Chiandussi G, Alovisi M, Cantatore G, Castellucci A, et al. Root canal anatomy preservation of WaveOne reciprocating files with or without glide path. J Endod. 2012;38(1):101-4. doi:10.1016/j.joen.2011.09.030

3. Berutti E, Chiandussi G, Paolino DS, Scotti N, Cantatore G, Castellucci A, et al. Canal shaping with WaveOne Primary reciprocating files and ProTaper system: a comparative study. J Endod. 2012;38(4):505-9. doi:10.1016/j.joen.2011.12.040

4. Lim YJ, Park SJ, Kim HC, Min KS. Comparison of the centering ability of Wave One and Reciproc nickel-titanium instruments in simulated curved canals. Restor Dent Endod. 2013;38(1):21-5. doi:10.5395/rde.2013.38.1.21

5. Marzouk AM, Ghoneim AG. Computed tomographic evaluation of canal shape instrumented by different kinematics rotary nickel-titanium systems. J Endod. 2013;39(7):906-9. doi:10.1016/j.joen.2013.04.023

6. Elnaghy AM, Elsaka SE. Evaluation of root canal transportation, centering ratio, and remaining dentin thickness associated with ProTaper Next instruments with and without glide path. J Endod. 2014;40(12):2053-6. doi:10.1016/j.joen.2014.09.001

7. Ruddle CJ, Machtou P, West JD. The shaping movement: fifth-generation technology. Dent Today. 2013;32(4):94, 96-9.

8. Weine FS, Kelly RF, Lio PJ. The effect of preparation procedures on original canal shape and on apical foramen shape. J Endod. 1975;1(8):255-62. doi:10.1016/S0099-2399(75)80037-9

9. Ajuz NCC, Armada L, Gonçalves LS, Debelian G, Siqueira Jr JF. Glide path preparation in S-shaped canals with rotary pathfinding nickel-titanium instruments. J Endod. 2013;39(4):534-7. doi:10.1016/j.joen.2012.12.025

10. Giuliani V, Di Nasso L, Pace R, Pagavino G. Shaping ability of WaveOne primary reciprocating files and ProTaper

\section{Conclusion}

It can be concluded that PTN produced less canal transportation than PTU and WO systems; however, R exhibited better centering ability than PTN.

\section{Acknowledgements}

This study was partially funded by Fundação de Amparo à Pesquisa do Estado do Rio de Janeiro - FAPERJ grants E-26/111.690/2013, E-26/201.491/2014 and E-26/010.001243/2015.

system used in continuous and reciprocating motion. J Endod. 2014;40(9):1468-71. doi:10.1016/j.joen.2014.02.024

11. Silva EJN, Tameirão MD, Belladonna FG, Neves AA, Souza EM, De-Deus G. Quantitative transportation assessment in simulated curved canals prepared with an Adaptive Movement System. J Endod. 2015;41(7):1125-9. doi:10.1016/j.joen.2015.02.028

12. Schneider CA, Rasband WS, Eliceiri KW. NIH Image to ImageJ: 25 years of image analysis. Nat Methods. 2012;9(7):671-5. doi:10.1038/nmeth.2089

13. Lee TC, Kashyap RL, Chu CN. Building skeleton models via 3-D medial surface/axis thinning algorithms. Comput Vis Graph Image Process. 1994;56(6):462-78. doi:10.1006/cgip.1994.1042

14. Zhao D, Shen Y, Peng B, Haapasalo M. Micro-computed tomography evaluation of the preparation of mesiobuccal root canals in maxillary first molars with Hyflex CM, Twisted Files, and K3 instruments. J Endod. 2013;39(3):385-8. doi:10.1016/j.joen.2012.11.030

15. Junaid A, Freire LG, Bueno CES, Mello I, Cunha RS. Influence of single-file endodontics on apical transportation in curved root canals: an ex vivo microcomputed tomographic study. J Endod. 2014;40(5):717-20. doi:10.1016/j.joen.2013.09.021

16. Freire LG, Gavini G, Cunha RS, Santos M. Assessing apical transportation in curved canals: comparison between cross-sections and micro-computed tomography. Braz Oral Res. 2012;26(3):222-7. doi:10.1590/S1806-83242012000300007

17. Gergi R, Osta N, Bourbouze G, Zgheib C, Arbab-Chirani

$\mathrm{R}$, Naaman A. Effects of three nickel titanium instrument systems on root canal geometry assessed by micro-computed tomography. Int Endod J. 2015;48(2):162-70. doi:10.1111/iej.12296

18. Roane JB, Sabala CL, Duncanson MG Jr. The "balanced force" concept for instrumentation of curved canals. J Endod. 1985;11(5):203-11. doi:10.1016/S0099-2399(85)80061-3 
19. Southard DW, Oswald RJ, Natkin E. Instrumentation of curved molar root canals with the Roane technique. J Endod. 1987;13(10):479-89. doi:10.1016/S0099-2399(87)80015-8

20. Çapar ID, Ertas H, Ok E, Arslan H, Ertas ET. Comparative study of different novel nickel-titanium rotary systems for root canal preparation in severely curved root canals. J Endod. 2014;40(6):852-6. doi:10.1016/j.joen.2013.10.010

21. Saber SE, Nagy MM, Schäfer E. Comparative evaluation of the shaping ability of WaveOne, Reciproc and OneShape single-file systems in severely curved root canals of extracted teeth. Int Endod J. 2015;48(1):109-14. doi:10.1111/iej.12289

22. Bürklein S, Hinschitza K, Dammaschke T, Schäfer E. Shaping ability and cleaning effectiveness of two single-file systems in severely curved root canals of extracted teeth: Reciproc and WaveOne versus Mtwo and ProTaper. Int Endod J. 2012;45(5):449-61. doi:10.1111/j.1365-2591.2011.01996.x
23. De-Deus G, Vieira VTL, Silva EJN, Lopes H, Elias $\mathrm{CN}$, Moreira EJ. Bending resistance and dynamic and static cyclic fatigue life of Reciproc and WaveOne large instruments. J Endod. 2014;40(4):575-9. doi:10.1016/j.joen.2013.10.013

24. You SY, Kim HC, Bae KS, Baek SH, Kum KY, Lee W. Shaping ability of reciprocating motion in curved root canals: a comparative study with microcomputed tomography. J Endod. 2011;37(9):1296-1300. doi:10.1016/j.joen.2011.05.021

25. Diemer F, Calas P. Effect of pitch length on the behavior of rotary triple helix root canal instruments. J Endod. 2004;30(10):716-8. doi:10.1097/01.DON.0000125877.26495.69

26. Bürklein S, Poschmann T, Schäfer E. Shaping ability of different nickel-titanium systems in simulated S-shaped canals with and without glide path. J Endod. 2014;40(8):1231-4. doi:10.1016/j.joen.2014.01.043 